\title{
Technology and Organizational Evolution: An Institutionalisation Perspective
}

\author{
Azadeh Pishdad, Abrar Haider and Andy Koronios \\ University of South Australia, Adelaide, Australia
}

\begin{abstract}
In contemporary business organizations, technology provides the foundation around which organizations evolve and mature. It not only aids organizations in enabling strategic business objectives through automation of operations, but with their information processing and decision support capabilities, these technologies also aid in business planning and management. Thus, the scope of these technologies extends from strategic enablers to strategic advisors. The literature suggests various perspectives on the role of technology in organization, i.e., techno-centric, humancentric, and technology institutionalisation. This paper aims to look at technology lifecycle process, through the lens of technology institutionalisation perspective. According to the institutional view and theories, there are various sub institutions operating in a broader environment of organization, such as organizational culture, social structure, and competitive environment. The organization thrives on the mutual interactions of these sub institutions and establishes its legitimacy. When technology becomes institutionalised, it is taken for granted by its users within the organization. This means that they are comfortable with technology and can employ its features effectively in their routine activities without requiring functional consultant or coach support. Moreover, an overview of literature on technology deinstitutionalisation and institutional change is presented in this paper which aims to study how old technologies of the organization and legacy systems are changed and replaced with new ones.
\end{abstract}

Keywords: Technology institutionalisation; Institutional theory; Institutional change; Technology deinstitutionalisation.

\section{Introduction}

Technology ${ }^{1}$ in an organization evolves through continuous interaction with other organizational sub-institutions like people, culture, technological infrastructure, customers, competitors, suppliers and etc.

\footnotetext{
1 Technology in this paper refers to hardware, software, communication networks, and systems that acquire, process, store, and deliver information to external and internal stakeholders in order to facilitate business processes. Here the term technology focuses on information systems, however, also envelops information technology
}

Technology implementation in contemporary business organizations, thus, should not be viewed as simple installation and one off endorsement of technology; instead the organization should engage in the process of technology assimilation/ institutionalisation to maintain its legitimacy, technical cohesion, and economic fitness on an on-going basis. The literature suggests different approaches to define the role of technology through its lifecycle, i.e., techno-centric, human-centric, and innovation-institutionalisation perspectives. Each of these perspectives, mainly, emphasizes one aspect of technology

Copyright (C) 2012 Azadeh Pishdad, Abrar Haider and Andy Koronios. This is an open access article distributed under the Creative Commons Attribution License unported 3.0, which permits unrestricted use, distribution, and reproduction in any medium, provided that original work is properly cited. Contact author: Azadeh Pishdad E-mail: pisay001@mymail.unisa.edu.au 
implementation more than others. For example Rogers (2003) considers mainly the technical characteristics of a technological innovation and argues that people judge a technology and decide to adopt or reject it based on their perceptions of five attributes of it, i.e., relative advantage, compatibility, complexity, trialability, and observability. Matching between user task needs and the available functionality of the technology is mainly the focus of task technology fit theory (TTF). However, user's attitudes toward a particular technology based on their perceived usefulness and ease of use comprises the determinants of technology acceptance model (TAM) (Davis et al. 1989; Goodhue and Thompson 1995; Wixom and Todd 2005). Technology-organizationenvironment (TOE) framework explores how technology lifecycle process is influenced by the technological, organizational, and environmental context (Tornatzky and Fleisher 1990), and the theory of social shaping of technology (Mackenzie and Wajcman 2001; Law 2004; Latour 2005) explores the effects of social, organizational, and cultural factors on the content of technology and the processes involved in introduction of technology to an organization. However, for better understanding of organization and their evolution, it is necessary to take into account different dimensions such as social, technical, organizational, political, competitive and institutional environment, internal system and structure, and the legal and cultural rules and obligations that the organization are conformed to. Furthermore, the literature review leads us to believe that mostly concepts related to innovationinstitutionalisation perspective such as institutional theory, institutional pressures and institutional change are used in political and social studies. However, there is an urgent need to study the effects of these concepts on technology implementation and its lifecycle as well.

This paper aims to look at technology lifecycle process, through the lens of technology institutionalisation perspective.
When technology is institutionalised, its usage within the organization becomes a routine activity, in the way that organizational actors could not think about doing their day-to-day job responsibilities without using it. In addition, this paper reviews the literature on technology deinstitutionalisation and institutional change to study how old technologies of the organization (legacy system) are changed and replaced with new ones.

This paper is structured as follows. The next section explains different approaches proposed by literature to define the concept of technology in organizations, followed by more granular analysis of innovationinstitutionalisation perspective and various trends and streams to institutionalism and institutional thinking. Then, an overview of institutional theory and three types of institutional isomorphic pressures which are the essential part of institutional and neoinstitutional theory is presented. The next section reviews the effects of institutional change/ evolution on technology lifecycle as the last stage of it. Finally, the last section provides conclusions, and directions for future research.

\section{Different Perspectives on the Concept of Technology in Organizations}

Techno-centric perspective and humancentric perspective are two main schools in defining the role of technology in organizations. The former school views technology as discontinuous, revolutionary leaps beyond direct human control and mostly by autonomous forces within which technology mostly plays a deterministic role (O'Donoghue et al. 2001; Munir and Phillips 2002; MacDougall 2011). In contrast, the latter school views technology as a product of ongoing human actions in developing, appropriating and changing technology (Orlikowski 2000; Lamb and Kling 2003; Law 2004; Suchman 2007; Elle et al. 2010). However, none of these philosophies are selfcompleted and the successful structure should take into account both perspectives (Orlikowski 1992; Orlikowski 2007). These 
two set of theories focus on the implementation of technology in organizations. These theories have, therefore, been used extensively in research and practice. However, technologies like information systems are much more than simple installation and endorsement of technology. The role and scope of information systems evolves continuously, such that the organizations evolve with their evolution. Therefore, there is a need to bridge up the gap between techno-centric perspective, human-centric perspective, and innovation-institutionalisation perspective and theories.

According to the institutional view and theories, there are various sub institutions operating in a broader environment of organization, such as organizational culture, social structure, and competitive environment. The organization thrives on the mutual interactions of these sub institutions and establishes its legitimacy (DiMaggio and Powell 1983; Powel and DiMaggio 1991; Grewal and Dharwadkar 2002; Zsidisin et al. 2005; Delmestri 2007; Greenwood 2008).

\section{Technology- Perspective}

Institutionalisation

An organization as an institution evolves through the mutual interactions of various organizational sub-institutions. Technology works as the binding factor that shapes organizations and gives them their existing form and legitimacy by integrating together these sub-institutions. The form and legitimacy define how organizations evolve their structures, culture, and systems. Institutions are social structures composed of cultural-cognitive, normative, and regulative elements that, together with resources and associated activities, bring stability and meaning to social life (Scott 2001). The organizational legitimacy, thus, achieved through social acceptability, credibility, and cultural support, derives the institution (Delmestri 2007; Weerakkody et al. 2009).
Institutional theory is gaining increasing attention in technology management research as a novel theoretical perspective (Powel and DiMaggio 1991; Greenwood 2008; Weerakkody et al. 2009; Currie 2011). Activities involving in development and use of technologies are subject to social, cultural, organizational, technical, and other institutional pressures. These pressures could be from external sources such as competition and customers, and government agencies as well as from legitimated norms, rules, and logics embedded within the organization. Organizations may respond to these pressures by conforming to technology mandates, or modifying their business practices to fit the technology. As a result, organizations address the opportunity for social approval and/or legitimacy. According to Powel and DiMaggio (1991), organizations as institutions are viewed as independent variables influenced not only by direct consequences of individuals' attributes and stakeholders motives, but also by cognitive and cultural explanations which are continuously reproduced through the socialization process. In summary, institutionalisation process embodies both objectification (i.e., the articulation of ideals, discourses and techniques), and subjectification (i.e., individuals' enactment through role development), whereby organizational routines shape and are shaped by its sub-institutions (Powel and DiMaggio 1991; Hasselbladh and Kallinikos 2000; Scott 2001; Dambrin et al. 2007; Scheirer 2005; Currie 2011; Abrutyn and Turner 2011). In addition, Institutions are subject to incremental and discontinuous change processes. Change is natural, almost inevitable and progressive. It takes decades for the need for change to be endorsed (Oliver 1992; Greenwood et al. 2002; Seal 2003; Clegg and Bailey 2008). According to system theory, organizational subinstitutions are interdependent and changes in one will affect whole system (entropy). Thus, changes in the technical infrastructure of an organization will affect whole organization and its operational environment which may result in deinstitutionalisation of 
current forms and practices and reinstitutionalisation of another technological infrastructure. More detailed description on institutional change process is provided in the rest of this article.

\section{Two Main Trends in Institutional Thinking}

Theories related to institutional thinking are mainly divided into two main trends, i.e., macro and micro level (Zucker 1987; Cleg 1990). At the macro-level, external and environmental characteristics are considered as the main conductors of institutionalised behavior. Coercive, normative, and mimetic [explained in the following section] are three isomorphic mechanisms through which organizations try to excel in their practice of social rules, ideals, and practices by aligning themselves with the environmental conditions (Meyer and Rowan 1977; Powel and DiMaggio 1991; Greenwood 2008). At the micro-level, institutionalised behavior is reproduced as a result of institutionalisation. This behavior is initially socially constructed and become stabilized. However, over time, the social background which led to the emergence of that behavior will be forgotten, as a result of discontinuous and incremental change process (Schutz 1962; Berger and Luckmann 1967; Baptista 2009). Lynne Zucker (1977) adopts the micro-level thinking to define three stages of technology institutionalisation process, i.e., habitualisation (the production of shared social meanings), objectivation (the process through which facts become independent as a reality experienced in common with others), and sedimentation (the process by which objectified facts become part of routine behavior). Later, she proposed the institutional- based trust theory constituting two key theoretical constructs, i.e., background expectation and constitutive expectation (Schutz 1962; Garfinkel 1967; Zucker 1986).

According to background expectation perspective, human perception of events and objects is similar and shared among all individual within one social setting. Schutz
(1962) argues people accept the world as how it is presented to them, with all its inherent typifications of behavior. These typifications result from sedimentation of individual's experience through which the reality is taken for granted. People also interpret new events and experiences on the basis of their understanding and perception of these typifications. Thus, when a technology becomes institutionalised, it is taken for granted by actors within the social system and typifications (cultural beliefs and scripts) become established as authoritative guidelines for organizational behavior. Garfinkel (1967) conceptualize constitutive expectation as norms and procedural rules which are constructing cognitive guidance system to assure whether the organization and its individuals play their role correctly and in a desirable way and their behavior is acceptable and reasonable. Thus, through establishing rules and governance for the gradual embedding of technology within the organizational social fabric and expected formal functioning, technology is institutionalised and formalized its use in the organization.

\section{Different Approaches to Institutionalism}

Organizations react to institutional forces in many different ways according to their organizational structure, culture, stockholders, and field of business (Scott 2001). There exist several approaches to institutionalism, i.e. normative, rational choice, historical, empirical, and constructivist. Based on the normative institutionalism, 'logic of appropriateness' is the best way to describe the behavior of individuals within an organization; as normative standards, moral templates, and cognitive scripts are the major social repositories of values shaping the actions of those acting within them (Hall and Taylor 1996; Peters 2000). Rational choice institutionalism views institutions as arrangements of rules, inducements and incentives, which influence members of institutions to behave appropriately in response to basic components of institutional 
structure to maximize their utilities. However, some preferences of the individuals in responding to rules, inducements and incentives remain unchanged (Hall and Taylor 1996; Peters 2000; Shepsle 2005). The third approach to institutionalism is historical, which relies on the concept of 'path dependency'. The idea behind this concept is that the inception of an institution will have continued effects over its behavior for the remainder of its existence, which explains sustainability and persistence of strategies, structure and actions. Empirical institutionalism answers the questions regarding organizational differences in strategy and policy choices and institutional stability according to their formal and informal structures (Hall and Taylor 1996; Peters 2000; Pierson and Skocpol 2002). Finally, constructivist institutionalism is the newest approach to institutional analysis which describes the role of ideas and discourses in organizational politics. This provides a more dynamic approach to institutional change than the previous mentioned approaches (Schmidt 2008).

\section{Institutional Isomorphic Pressures}

Institutional isomorphism is a process in which organizations try to excel in their practice of social rules, ideals, and practices by aligning themselves with the environmental conditions. These institutional pressures push organizations to adopt shared notions and routines. Thus, the interpretation of intention to adopt technology and the prevailing context of the organization is affected by its perception of these pressures. Coercive (constraining), normative (learning), and mimetic (cloning) are three isomorphic mechanisms which influence organizations in gaining operational efficiency, similarity with peers, and success (DiMaggio and Powell 1983; Powel and DiMaggio 1991; Greenwood 2008).

Regulative, cultural-cognitive, and normative are three institutional views representing theses isomorphic pressures which are not mutually exclusive and may be interdependent. For example, organizational actors may interpret, negotiate and socially construct the meaning of rules and regulations on the basis of normative and cultural-cognitive considerations (Edelman et al. 1999), which are also useful in explaining the diffusion of technology innovation (Scott 2001; Currie 2011). Figure 1 demonstrates these three institutional isomorphic mechanisms and the concepts related to each of them.

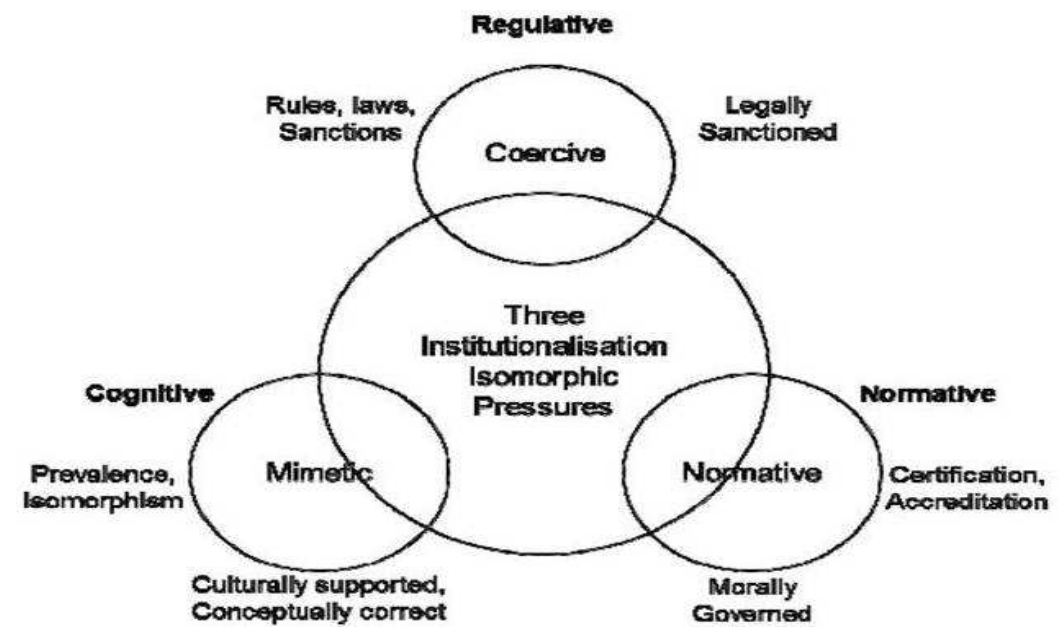

Fig 1. Institutional Isomorphism Mechanisms/ Pressures (Developed for This Research) 
The coercive isomorphism occurs by organizational desire to conform to laws, rules, and sanctions established by institutional actors or sources. This similarity results in gaining legitimacy and external validation that improves the organization's access to resources (Bjorck 2004). Negative sanctioning is the central component of coercive institutional process, as it includes rules, regulations, and laws that are used to constrain organizational actions. The coercive pressure exerted on organizations by other organizations upon which they are dependent (DiMaggio and Powell 1983; Scott 2001). Constituents such as suppliers and customers mainly hold resources organizations need, e.g., new business contracts or funding (Grewal and Dharwadkar 2002). As a result, a powerful organization can exert pressure on these partners by raising requirements such as conforming to a security standard as a condition for customer requirements (Zsidisin et al. 2005). The dependent organizations will call attention to the asymmetry of power when they perceive coercive pressure and, thus, better understand the consequences of adopting or not adopting the technology. In general, the dependent partner tends to comply with the powerful firm's demand and be inclined to adopt and routinize technology usage into daily operation process in order to maintain relationships with powerful partners, to make transaction process more efficient, to secure their market status and to continue accessing to scarce resources provided by the powerful firm (DiMaggio and Powell 1983; Scott 2001; Jei and Sia 2011).

The normative mechanism mostly concerns the moral and pragmatic aspect of legitimacy by assessing whether the organization plays its role correctly and in a desirable way. It can refer to the positive pursuit of valued ends, as well as negative deviations from goals and standards (Scott 2001). The progressive use of IT in an organization could be viewed as the result of normative influences, such as, ATM service is a standard service offering by retail banks, and banks who are not offering this service are more in the risk of damaging their legitimacy in the view of their industry and other institutions. Normative pressures evolve through firmsupplier and firm-customer interorganizational channels as well as other trading partners, and professional and industry institutions (Powell and DiMaggio 1991; Liang et al. 2007). For instance, the frequency of technology usage among an organization's suppliers and customers may wake up decision makers' awareness of the technology and ignite organization's inclination to adopt it. Furthermore, compliance with norms with respect to environmental concerns can lead to profitability, e.g., reducing organizational cost by conforming to an environmental norm such as reduction in wastage of efforts, time, and resources (DiMaggio and Powell 1983; Delmestri 2007; Scott 2001; Jei and Sia 2011).

The mimetic isomorphism is a cause of organizational tendency to remain similar to its peers in order to get a positive evaluation from the organizational environment. This mechanism results in reducing uncertainty, improving predictability, and benchmarking organizations who are performing at or near optimum level (Scott 2001; Teo et al. 2003). Organizations who are structurally equivalent and having similar economic network position, similar goals, produce, and commodities are more likely to imitate each other. Moreover, organizations mimic because they anticipate similar benefits. Therefore, when an organization starts adopting and implementing a technology, other competitors from the same industry becomes aware of it and considers adopting it (Scott 2001; Katsumata 2011). However, conceptually, it is not clear whether firms mimic other organizations to gain legitimacy rather than technological or economic advantage (Staw and Epstein 2000). Noncompliance with each of these mechanisms comes with a risk of costly penalties, or in the worst case with the death of organization (Baptista 2009). 


\section{Institutional Change}

Traditionally, research have been mainly focused on the institutional effects of technologies by using three mechanisms of institutional isomorphism and little attention has been given to study how technologies could be a part of the process of deinstitutionalisation and reinstitutionalisation. Deinstitutionalisation has only recently begun to attract attention as it is increasingly recognized to be equally central to institutional process (Greenwood et al. 2002; Clegg and Bailey 2008). When institutional isomorphic pressures increase, the institutionalisation process emerges. On the other hand, when they decrease, deinstitutionalisation process starts. Deinstitutionalisation is, therefore, a result of institutional change, erosion of existing institutions and creation of new ones (Seal 2003). Deinstitutionalisation also facilitates unlearning in the organization to learn new facts, realities, and concepts. Through the deinstitutionalisation, institutions weaken and disappear because of new beliefs and practices (Scott 2001). The process of institutional change is usually evolutionary and path dependent which is shaped by existing institutions (Siti-Nabiha and Scapens 2005).

Greenwood et al. (2002) introduce a model for institutional change which is described here. Disequilibrium is the first stage of this model which occurs when events or jolts destabilize established practices. These events could be in the form of social and technological disruptions, competitive discontinuities, or regulatory changes. These changes result in deinstitutionalisation of forms and practices, disturbance of socially constructed norms, introducing new ideas, emergence of new players, domination of existing actors, and institutional entrepreneurship (Stage 2). In the third stage, i.e., preinstitutionalisation, organizations start to innovate independently, and look for technically better and viable solutions to perceived problems. The next stage "theorization" involves both the specification of the failings of existing norms and practices for which a local innovation is a solution or treatment, and the justification of new norms, practices, and technical innovations in terms of moral or pragmatic considerations. These concepts have been neglected conceptually and empirically in the extent literature. If new ideas were more appropriate than existing ones, they would diffuse throughout an organization or among organizations in a given field; thus, new norms and practices take on a greater degree of legitimacy and, in turn, become institutionalised. This is a journey from theoretical formulation to social movement and institutional imperative which give technological innovations moral and pragmatic legitimacy. When innovations "objectify" or gain social consensus concerning their pragmatic value, they diffuse into organization, and various organizational actors can observe the institution and its interactions, and thus the new round of socialization starts. The next stage, i.e., full reinstitutionalisation occurs as the result of cognitive legitimacy. This is when ideas are taken-for-granted as a natural and appropriate arrangement and are accepted as the definitive way of organizational behaviour. After technology becomes sedimented and taken- for-granted by actors in a social system, they may even not recognize that their behaviour is partly controlled by the institution (Bjorck 2004; Scott 2008; Baptista 2009).

Oliver (1992) introduces three main sources of pressures that can lead to the erosion of legitimacy or the taken for grantedness which characterize institutions. These major antecedents are functional, political, and social pressures [table 1]. Perceived problems in performance levels, or changes in the perceived utility associated with institutionalised practices are the main drivers of functional pressure that influence deinstitutionalisation and institutional change. These functional pressures may be tied to intraorganizational and environmental changes, e.g., technical aspects of activity or intensified competition 
for resources (Lounsbury 2002; Dacin et al. 2002). If the perceived performance level of institution is not acceptable by actors constituting it, erosion of existing institution will happen over time. Political pressures for deinstitutionalisation arise from shifts in the pattern of interests and underlying distributions of power that have supported and legitimated existing institutional arrangements. These shifts may happen as a result of performance crises, re-valuation of the instrumental value of the institution, environmental changes, or shifts in the distribution of power that compel organizations to question the legitimacy of a given practice. For example, Greenwood et al. (2002) study institutional change within the accounting profession in Canada, and the way professional associations respond to market forces and technological shifts for a new range of services altered in the political context of accounting firms, and how they legitimated the change. These forces result in redefining and extending the scope of financial services beyond traditional accounting services and by incorporating management consulting, financial advisory and legal services. In this case, professional associations legitimated the change over a 20-year period by referencing the prevailing values and practices of the profession, particularly around service to clients. In this study, deinstitutionalisation addressed as a process of discourse through which change is debated and endorsed (Goetz and Peters 1999; Burns and Scapens 2000; Dambrin et al. 2007). Finally, social pressures are mainly associated with increased differentiation among members of a group (such as increasing workforce diversity), structural changes to organizations that reduce the coherence of beliefs and practices, and changes in social expectations or laws that might prevent the continuation of a practice (Dacin et al. 2002; Clegg and Bailey 2008). These social pressures results in the erosion of the taken for granted assumptions and shared agreements upon which institutions depend, thereby resulting in deinstitutionalisation. In summary, these functional, political, and social pressures will not automatically lead to a breakdown in institutional norms. They should be interpreted, given meaning, and responded to by actors within organizations (Scott 2001; Dacin et al. 2002). In addition, in the research done by Siti-Nabiha and Scapens (2005), it was shown that deinstitutionalisation is not just an organizational response to external (institutional) pressures and demands; rather it can occur through the working out of resistance to embrace change. The evolutionary process of change constitutes both stability and change simultaneously that states they are not necessarily contradictory or opposing forces (Burns and Scapens 2000; Siti-Nabiha and Scapens 2005).

Table 1: Three Main Sources of Institutional Change (Oliver (1992))

\begin{tabular}{|l|l|}
\hline Pressure & Main drivers \\
\hline Functional & $\begin{array}{l}\text { Perceived problems in performance levels, changes in the perceived utility } \\
\text { associated with institutionalised practices, and Intensified competition for } \\
\text { resources }\end{array}$ \\
\hline Political & $\begin{array}{l}\text { Shifts in the pattern of interests and underlying distributions of power. } \\
\text { performance crises, re-valuation of the instrumental value of the institution, } \\
\text { environmental changes }\end{array}$ \\
\hline Social & $\begin{array}{l}\text { Increased differentiation among members of a group (such as increasing } \\
\text { workforce diversity), structural changes to organizations, changes in social } \\
\text { expectations or laws }\end{array}$ \\
\hline
\end{tabular}

Reinstitutionalisation refers to departing from one institutionalisation and arriving into another institutional form and practices which are organized around different principle and rules (Currie 2011). Full reinstitutionalisation occurs as the result of 
cognitive legitimacy. This is when ideas are taken for granted as a natural and appropriate arrangement and are accepted as the definitive way of organizational behaviour.

\section{Conclusions and Future Directions}

Technology institutionalisation is an evolutionary and nonlinear process and its success depends on a number of contextual, technical, environmental, social, cultural, and other institutional factors and their mutual interactions. These interactions contribute to organizational maturity, legitimacy, and success and define technology implementation, institutionalisation, deinstitutionalisation and reinstitutionalisation in the organization. Furthermore, although organization itself is an institution, it consists of a variety of sub institutions. The mutual interactions of these institutional pressures not only define technology implementation/ assimilation, but also have bearing on institutionalisation of technology through the process of institutional isomorphism. The aim of this paper is, thus, to review literature on how technology institutionalisation occurs in organizations, and more precisely how institutional logics are diffused within organizations through three isomorphic processes i.e., coercive, mimetic and normative. Moreover, how these technologies are changed by the process of institutional change, deinstitutionalisation, and reinstitutionalisation. This paper concludes considering the effects of institutional pressures provide new insights into how the behaviors of individuals within an organization are influenced by organizational norms, values, regulations, and culture. On the contrary, how they may result in deinstitutionalisation and reinstitutionalisation of organizational forms and practices.

Some research themes or dimensions that would be interesting to investigate are including technology institutionalisation challenges, factors influencing and are influenced by the institutional environment; conditions on which stable structures become destabilized and call for change; the consequences of deinstitutionalisation process for maintaining new institutional arrangements; relationships between organizational characteristics, external pressures and institutional process; reasons of resistance to change. These themes are important to explore because they provide foundation for understanding how technologies in general and information technologies in particular become embedded in the organization.

\section{References}

Abrutyn, S. \& Turner, J. (2011). "The Old Institutionalism Meets the New Institutionalism," Sociological Perspectives, 54(3), 283-306.

Baptista, J. (2009). "Institutionalisation as a Process of Interplay between Technology and Its Organizational Context of Use," Journal of Information Technology, 24(4), 305-319.

Berger, P. L. \& Luckmann, T. (1967). The Social Construction of Reality: A Treatise in the Sociology of Knowledge, London: The Penguin Press, P. 249.

Bjorck, F. (2004). 'Institutional Theory: A New Perspective for Research into IS/IT Security in Organizations, HICSS, P. 70186b,' Proceedings of the 37th Annual Hawaii International Conference on System Sciences (HICSS'04) - Track 7.

Burns, J. \& Scapens, R. W. (2000). "Conceptualising Management Accounting Change: An Institutionalist Framework," Management Accounting Research, 11(1), 325.

Clegg, S. R. (1990). Modern Organizations: Organization Studies in the Post-Modern World, London: Sage Publications.

Clegg, S. R. \& Bailey, J. R. (2008). International Encyclopedia of Organization Studies. Thousand Oaks: Sage Publications. 
Currie, W. L. (2011). Institutional Theory of Information Technology. The Oxford Handbook of Management Information Systems: Critical Perspectives and New Directions: 137-173.

Dacin, M. T., Goodstein, J., Scott, W. R. (2002). "Institutional Theory and Institutional Change: Introduction to the Special Research Forum," The Academy of Management Journal, 45(1), 43-56.

Dambrin, C., Lambert, C. \& Sponemb, S. (2007). "Control and Change- Analysing the Process of Institutionalisation," Management Accounting Research, 18(2), 172-208.

Davis, F. D., Bagozzi, R. P. \& Warshaw, P. R. (1989). "User Acceptance of Computer Technology: A Comparison of Two Theoretical Models," Management Science, 35(8), 982-1003.

Delmestri, G. (2007). 'Institutional Theory. International Encyclopedia of Organization Studies,' Thousand Oaks, CA: Sage.

Dimaggio, P. J. \& Powell, W. W. (1983). "The Iron Cage Revisited: Institutional Isomorphism and Collective Rationality in Organizational Fields," American Sociological Review, 48 (2), 147-160.

Edelman, L. B., Uggen, C. \& Erlanger, H. S. (1999). "The Endogeneity of Legal Regulation: Grievance Procedures as Rational Myth," American Journal of Sociology, 105(2), 406-454.

Elle, M., Darnmann, S., Lentsch, J. \& Hansen, K. (2010). "Learning from the Social Construction of Environmental Indicators: From the Retrospective to the Pro-Active Use of SCOT in Technology Development," Building and Environment, 45(1), 135-142.

Garfinkel, H. (1967). Studies in Ethnomethodology, Englewood Cliffs, NJ: Prentice-Hall, P. Xvi, 288 P.

Goetz, K, H. \& Peters, B. G. (1999). 'Institutional Theory and Political Executives:
Creating Executive Organizations East and West,' Paper Presented at Conference on Institutional Theory, Ross Priory, Dunb., Scotland, October 18-19.

Goodhue, D. L. \& Thompson, R. L. (1995). "Task-Technology Fit and Individual Performance," MIS Quarterly, 19(2), 213-236.

Greenwood, R. (2008). 'The SAGE Handbook of Organizational Institutionalism,' Los Angeles: Sage.

Greenwood, R., Suddaby, R. \& Hinings C. R. (2002). "Theorizing Change: The Role of Professional Associations in the Transformation of Institutionalised Fields," Academy of Management Journal, 45(1), 5880.

Grewal, R. \& Dharwadkar, R. (2002). "The Role of Institutional Environment in Marketing Channels," Journal of Marketing, 66(3), 82-97.

Hall, P. A. \& Taylor, R. C. R. (1996). "Political Science and the Three Institutionalisms," Political Studies, 44, 936-957.

Hasselbladh, H. \& Kallinikos, J. (2000). "The Project of Rationalization: A Critique and Reappraisal of Neo-Institutionalism in Organization Studies," Organization Studies, 21(4), 697-720.

Jei, W. \& Sia, C. L. (2011). The Process of RFID Assimilation by Supply Chain Participants in China: A Technology Diffusion Perspective on RFID Technology. In Proceedings of the 17th Americas Conference on Information Systems, Detroit, Michigan.

Katsumata, H. (2011). "Mimetic Adoption and Norm Diffusion: 'Western' Security Cooperation in Southeast Asia?," Review of International Studies, 37(2), 557-576.

Lamb, R. \& Kling, R. (2003). "Reconceptualizing Users as Social Actors in Information Systems Research," MIS Quarterly, 27(2), 197-236. 
Latour, B. (2005). Reassembling the Social: An Introduction to Actor-Network-Theory. Oxford, UK: Oxford University Press.

Law, J. (2004). After Method: Mess in Social Science Research. New York: Routledge.

Liang, H., Saraf, N., Hu, Q. \& Xue, Y. (2007). "Assimilation of Enterprise Systems: The Effect of Institutional Pressures and the Mediating Role of Top Management," MIS Quarterly, 31(1), 59-87.

Lounsbury, M. (2002). "Institutional Transformation and Status Mobility: The Professionalization of the Field of Finance," Academy of Management Journal, 45, 255266.

MacDougall, R. (2011). "The Technological Imperative in Canada: An Intellectual History (Review)," Labour (Halifax), 0700-3862, 67: 232-234.

Mackenzie, D. \& Wajcman, J. (Eds.) (2001). The Social Shaping of Technology (2nd Ed.) Buckingham: Open University Press.

Meyer, J. W. \& Rowan, B. (1977). "Institutionalised Organisations: Formal Structure as Myth and Ceremony," American Journal of Sociology, 83, 340-363.

Munir, K. A. \& Phillips, N. (2002). "The Concept of Industry and the Case of Radical Technological Change," The Journal of High Technology Management Research, 13(2), 279-297.

O'Donoghue, J., Singh, G. \& Dorward, L. (2001). "Virtual Education in Universities: A Technological Imperative," British Journal of Educational Technology, 32(5), 511-523.

Oliver, C. (1992). "The Antecedents of Deinstitutionalisation," Organization Studies, 13(4), 563-588.

Orlikowski, W. J. (1992). "The Duality of Technology: Rethinking the Concept of Technology in Organizations," Organization Science, 3(3), 398-427.
Orlikowski, W. J. (2000). "Using Technology and Constituting Structures: A Practice Lens for Studying Technology in Organizations," Organization Science, 11(4), 404-428.

Orlikowski, W. J. (2007). "Sociomaterial Practices: Exploring Technology at Work," Organization Studies, 28(9), 1435-1448.

Peters, B. G. (2000). 'Institutional Theory: Problems and Prospects,' Political Science Series 69, Institute for Advanced Studies, Vienna.

Pierson, P. \& Skocpol, T. (2002). "Historical Institutionalism in Contemporary Political Science," In Political Science: The State of the Discipline, Eds. I. Katznelson and H. V. Milner. New York: Norton, Pp. 445-88.

Powell, W. W. \& Dimaggio, P. J. (Eds.). (1991). The New Institutionalism in Organizational Analysis. Chicago: University of Chicago Press.

Rogers, E. M. (2003). Diffusion of Innovations, 5th Ed. Free Press, New York.

Scheirer, M. A. (2005). "Is Sustainability Possible? A Review and Commentary on Empirical Studies of Program Sustainability," American Journal of Evaluation, 26(3), 320347.

Schmidt, V. A. (2008). "Discursive Institutionalism: The Explanatory Power of Discourse," Annual Review of Political Science, 11, 303-326.

Schutz, A. (1962). 'Collected Papers: The Problem of Social Reality,' In M. Natanson (Ed.) the Hague: Martinus Nijhoff London, P. Xlvii, 361p.

Scott, W. R. (2001). Institutions and Organizations (2nd Ed.). Thousand Oaks, CA: Sage.

Seal, W. (2003). "Modernity, Modernization and the Deinstitutionalisation of Incremental Budgeting in Local Government," Financial Accountability and Management, 19(2), 93116. 
Shepsle, K. A. (2006). Rational Choice Institutionalism. In: Rhodes. R. A. W. et Al. (Eds.). Political Institutions. Oxford: Oxford University Press. 23-38.

Siti-Nabiha, A. K. \& Scapens, R. W. (2005). "Stability and Change: An Institutionalist Study of Management Accounting Change," Accounting Auditing and Accountability Journal, 18(1), 44-73.

Staw, B. M. \& Epstein, L. D. (2000). "What Bandwagons Bring-Effects of Popular Management Techniques on Corporate Performance, Reputation and CEO Pay," Administrative Science Quarterly, 45(3), 523556.

Suchman, L. A. (2007). Human-Machine Reconfigurations: Plans and Situated Actions. Second Edition, Cambridge: Cambridge University Press.

Teo, H. H., Wei, K. K. \& Benbasat, I. (2003). "Predicting Intention to Adopt Interorganizational Linkages: An Institutional Perspective," MIS Quarterly, 27, 19-49, 2003.

Tornatzky, L. G. \& Fleischer, M. (1990). The Processes of Technological Innovation. Lexington Books, Lexington, Massachusetts.

Weerakkody, V., Dwivedi, Y. K. \& Irani, Z. (2009). "The Diffusion and Use of Institutional Theory: A Cross-Disciplinary Longitudinal Literature Survey," Journal of Information Technology, 24(4), 354-368.

Wixom, B. H. \& Todd, P. A. (2005). "A Theoretical Integration of User Satisfaction and Technology Acceptance," Information Systems Research, 16(1), 85-102.

Zsidisin, G. A., Melnyk, S. A. \& Ragatz. G. L. (2005). "An Institutional Theory Perspective of Business Continuity Planning for Purchasing and Supply Management," International Journal of Production Research, 43 (16), 3401-3420.
Zucker, L. G. (1977). "The Role of Institutionalisation in Cultural Persistence," American Sociological Review, 42(5), 726743.

Zucker, L. G. (1986). "Production of Trust: Institutional Sources of Economic Structure, 1840-1920," Research in Organisational Behaviour, 8(1), 53-111.

Zucker, L. G. (1987). "Institutional Theories of Organization," Annual Review of Sociology, 13(1), 443-464. 